TechSights

\title{
The Property-Based Practical Applications and Solutions of Genetically Encoded Acetylcholine and Monoamine Sensors
}

\author{
Jun Chen, ${ }^{1,2,3}{ }^{\circledR}$ Katriel E. Cho, ${ }^{4,5}$ Daria Skwarzynska, ${ }^{4,5}$ Shaylyn Clancy, ${ }^{5,6}{ }^{\circledR}$ Nicholas J. Conley, ${ }^{4,5}$ \\ Sarah M. Clinton, ${ }^{7}$ Xiaokun Li, ${ }^{2}{ }^{\circledR}$ Li Lin, ${ }^{1,2}$ and ${ }^{\circledR}$ J. Julius $\mathrm{Zhu}^{3}$ \\ ${ }^{1}$ Department of Neurosurgery, First Affiliated Hospital of Wenzhou Medical University, ${ }^{2}$ Pharmaceutical Sciences Graduate Program, School of \\ Pharmaceutical Sciences, Wenzhou Medical University, Wenzhou, 325035, China, ${ }^{3}$ Department of Pharmacology, University of Virginia School of \\ Medicine, Charlottesville, Virginia 22908, ${ }^{4}$ Neuroscience Graduate Program, University of Virginia School of Medicine, Charlottesville, Virginia \\ 22908, ${ }^{5}$ Tools for Modern Neurobiology Class of 2020, University of Virginia School of Medicine, Charlottesville, Virginia 22908, ${ }^{6}$ Cell and \\ Developmental Biology Graduate Program, University of Virginia School of Medicine, Charlottesville, Virginia 22908, and ${ }^{7}$ School of Neuroscience, \\ Virginia Polytechnic Institute and State University, Blacksburg, Virginia 24061
}

Neuromodulatory communication among various neurons and non-neuronal cells mediates myriad physiological and pathologic processes, yet defining regulatory and functional features of neuromodulatory transmission remains challenging because of limitations of available monitoring tools. Recently developed genetically encoded neuromodulatory transmitter sensors, when combined with superresolution and/or deconvolution microscopy, allow the first visualization of neuromodulatory transmission with nanoscale or microscale spatiotemporal resolution. In vitro and in vivo experiments have validated several high-performing sensors to have the qualities necessary for demarcating fundamental synaptic properties of neuromodulatory transmission, and initial analysis has unveiled unexpected fine control and precision of neuromodulation. These new findings underscore the importance of synaptic dynamics in synapse-, subcellular-, and circuit-specific neuromodulation, as well as the prospect of genetically encoded transmitter sensors in expanding our knowledge of various behaviors and diseases, including Alzheimer's disease, sleeping disorders, tumorigenesis, and many others.

Key words: acetylcholine; norepinephrine; serotonin; dopamine; neuromodulation; synaptic transmission; superresolution and deconvolution microscopy

\section{Introduction}

Acetylcholine (ACh), the first identified neurotransmitter, mediates communication among various neurons and non-neuronal cells. In the CNS, cholinergic neurons originate primarily from three major nuclei (i.e., the basal forebrain nuclei, brainstem pedunculo-pontine, and lateral dorsal tegmental nuclei), which project widely throughout cortical and subcortical regions to modulate complex brain functions, including attention, cognition, and sleep-wake cycles (Picciotto et al., 2012; Ballinger et al., 2016). In addition, a few smaller cholinergic neuron populations in the regions, such as medial habenula and striatum, contribute to behaviors related to movement, motivation, and stress (Picciotto et al., 2012; Ballinger et al., 2016). Dysregulation of central cholinergic transmission plays a role in major brain disorders, including addiction, Alzheimer's disease, depression, epilepsy, Parkinson's disease,

Received June 10, 2020; revised Dec. 17, 2020; accepted Dec. 21, 2020.

We thank members of the J.J.Z. laboratory for comments and discussions; Drs. Henry Lester, Yulong Li, Loren Looger, and Lin Tian for sharing unpublished sensors and information; and the reviewers and editors for constructive suggestions and scholarly editing. JC, LL and JJZ reviewed the neuromodulation research and genetically encoded neurotransmitter sensors in this manuscript with input from all other co-authors. JJZ conceived the neurotransmitter sensor-based superresolution and deconvolution microscopic analysis method, and supervised the method development with input from LL.

The authors declare no competing financial interests.

Correspondence should be addressed to Li Lin at linliwz@163.com.

https://doi.org/10.1523/JNEUROSCI.1062-19.2020

Copyright $\odot 2021$ the authors and schizophrenia (Picciotto et al., 2012; Kruse et al., 2014; Ballinger et al., 2016). Beyond CNS, neurons and non-neuronal cells may release ACh to relay neuromuscular synaptic transmission and regulate functions of a variety of other tissues and organs (e.g., the heart, liver, and pancreas) (Wessler and Kirkpatrick, 2008; Kruse et al., 2014). Dysregulation of peripheral and non-neuronal cholinergic signals may initiate a plethora of pathologic conditions, including cardiovascular diseases, diabetes, immunodeficiency, and cancer (Kruse et al., 2014; Herring et al., 2019).

Norepinephrine (NE) is a monoamine neurotransmitter synthesized by neurons in the locus coeruleus, which project to a large variety of areas in the CNS (Aston-Jones and Cohen, 2005; Sara and Bouret, 2012; Schwarz and Luo, 2015). Through these diverse projections, noradrenergic neurons regulate multiple high-level cognitive functions, including attention, cognition, sleep-wake cycles, movement, and stress, many of which are modulated by cholinergic neurons as well. Dysregulated adrenergic transmission profoundly disrupts arousal and cognition, leading to disorders similar to those caused by dysregulated cholinergic transmission, such as Alzheimer's disease, autism, sleep disorders, mood disorders, Parkinson's disease, and schizophrenia (Aston-Jones and Cohen, 2005; Berridge et al., 2012; Jacob and Nienborg, 2018). In peripheral organs, dysregulation of adrenergic signals is responsible for many health problems, including cardiovascular diseases, immunodeficiency, and cancer (Wood and Valentino, 2017; Dantzer, 2018). 
A GPCR-based genetically

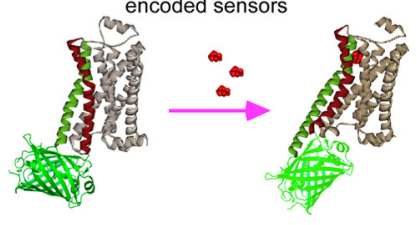

PBP-based genetically encoded sensors

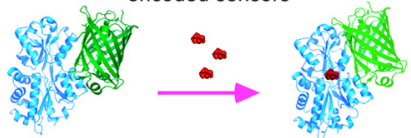

2n:

C Nano- or micro-scopic analysis with supreresolution and/or deconvolution microscopy

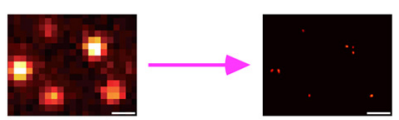

B

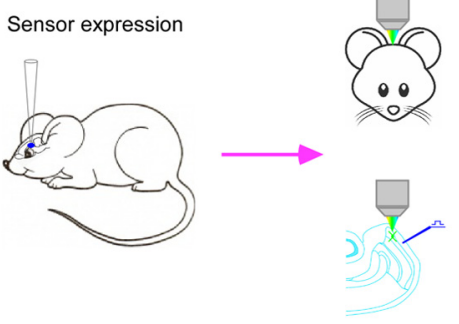

D 3D spatiotemporal profiling of neuromodulatory transmission

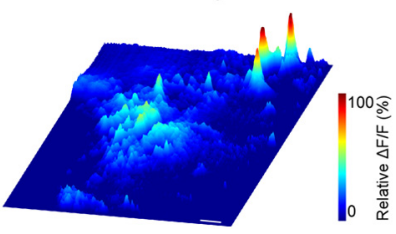

Figure 1. Profiling neuromodulatory transmission with genetically encoded sensors. $\boldsymbol{A}$, Schematic of designs of GPCR- and bacterial PBP-based genetically encoded sensors for neuromodulatory transmitters. $\boldsymbol{B}$, Schematic of expression, in vivo and ex vivo applications of genetically encoded sensors. $\boldsymbol{C}$, Schematic of superresolution and/or deconvolution microscopic analysis of image data obtained with genetically encoded sensors that allows nanoscale and microscale resolution of neuromodulatory transmission. $\boldsymbol{D}$, Spatiotemporal profiling of neuromodulatory transmission with genetically encoded sensors that permits decoding of fundamental properties of neuromodulatory transmission, such as transmitter spatial diffusion extent, number of release sites, release pool size, release probability, quantal size, and refilling rate.

Serotonin (5-hydroxytryptamine [5HT]) in the brain is synthesized by neurons in the brainstem raphe nuclei that innervate nearly every area in the brain and spinal cord (Jacobs and Azmitia, 1992; Okaty et al., 2019). Serotonergic neurons influence diverse behaviors, including appetite, attention, emotion, cognition, motivation, perception, sleep, social interaction, and sexuality (Berger et al., 2009; Okaty et al., 2019). It has been hypothesized that 5HT may have a unified functional role involved primarily in aversive processing in the brain (Dayan and Huys, 2009; Hu, 2016). Indeed, dysregulation of central serotonergic transmission has been implicated in a large group of anxiety and mood disorders, including panic disorder, social anxiety disorder, generalized anxiety disorder, post-traumatic stress disorder, obsessive-compulsive disorder, major depressive disorder, bipolar disorder, and schizophrenia (Ravindran and Stein, 2010). Serotoninergic signals also participate in functions of many other tissues and organs, and dysregulation of peripheral and non-neuronal serotonergic signals may cause a wide range of disorders, including cardiovascular diseases, respiratory defects, and metabolic and bowel disorders (Berger et al., 2009).

Dopamine (3,4-dihydroxyphenethylamine [DA]) is a monoamine transmitter that seems to functionally counteract $5 \mathrm{HT}$. Dopaminergic neurons primarily cluster in nine major cell groups in the brain, with those situated in the midbrain SNc and VTA best characterized (Bjorklund and Dunnett, 2007; Morales and Margolis, 2017). In contrast to other monoaminergic transmitters, dopaminergic neurons project to limited, specific brain regions, mainly the striatum, PFC and orbitofrontal cortex, amygdala, and associated structures (Bjorklund and Dunnett, 2007; Morales and Margolis, 2017). Dopaminergic transmission is critical for motor control and appetitive processing, involving particularly the reward-associated liking, wanting, and learning behaviors (Hu, 2016; Schultz, 2016). Disturbance of dopaminergic transmission contributes to a number of psychiatric conditions, such as addiction, Parkinson's disease, Tourette's syndrome, attention-deficit/hyperactivity disorder, and schizophrenia (Maia and Frank, 2011; Grace, 2016; Volkow et al., 2019).

Years of research have made an impressive progress in our understanding of neuromodulation, and the findings highlight the pivotal role of neuromodulation in myriad behaviors and diseases. However, many key features of cholinergic and monoaminergic transmission remain unresolved (Barbour and Hausser, 1997; Eban-Rothschild et al., 2018; Mohebi et al., 2019; Okaty et al., 2019), which has hampered efforts to define the physiological and pathologic mechanisms for the behaviors and diseases. For example, whether cholinergic and adrenergic signals differentially control attention and movement, and how they individually affect behaviors are still in debate. Likewise, whether serotonergic and dopaminergic signals act individually or complementarily to regulate aversion and appetition, and how they balance their efforts in different contexts remain elusive. Moreover, what synaptic properties of neuromodulatory transmission are altered under disease conditions and how the alterations may lead to the pathogenesis of neuromodulation-linked diseases are largely unknown.

The slow advance in understanding of synaptic properties of neuromodulatory transmission is due primarily to limitations of available tools that may quantitatively analyze cholinergic and monoaminergic transmission. Although the detection sensitivity of microdialysis, a frequently used method, has been improved in recent years, its poor spatial and temporal resolution remains an obstacle that precludes accurate assessment of the signal dynamics of cholinergic and monoaminergic transmission (Olive et al., 2000; Darvesh et al., 2011). With remarkable sensitivity and temporal resolution, patch-clamp recordings have served as the gold standard to delineate synaptic properties of glutamatergic and GABAergic transmission (Neher, 2015; Jackman and Regehr, 2017). However, this electrophysiology application is severely compromised when dealing with cells with minimal or no net neuromodulator-induced electrophysiological responses (Dani and Bertrand, 2007; Nadim and Bucher, 2014). Fast scan cyclic voltammetry provides excellent nanomolar sensitivity and millisecond temporal resolution, but this detection approach is hindered by its poor spatial resolution and inability to distinguish NE and DA (Robinson et al., 2008). Recent efforts have led to the development of fluorescence resonance energy transfer- and cell-based fluorescent $\mathrm{ACh}$ and monoamine sensors (Vilardaga et al., 2003; Muller et al., 2014). However, their low sensitivity and/or low resolution permit detection of only volume-size transmission, and are unable to resolve synaptic properties of cholinergic and monoaminergic transmission. These limitations inspire the desire to engineer user-friendly and broadly applicable genetically encoded neurotransmitter sensors that permit tissue-specific high-resolution measurements of neuromodulatory transmission (Lin and Schnitzer, 2016).

\section{Sensor properties}

In the last few years, close collaborations among tool engineers and biologists have created and validated several intensity-based genetically encoded sensors for $\mathrm{ACh}$ and monoamines. These sensors consist of a conformationally sensitive circularly permutated GFP (cpGFP) and a ligand-binding protein that alters cpGFP fluorescence by inducing conformational changes upon 
Table 1. Key properties of genetically encoded sensors for ACh and monoamines ${ }^{\mathrm{a}}$

\begin{tabular}{|c|c|c|c|c|c|}
\hline Sensors & Sensitivity $(\mu \mathrm{m})$ & $\Delta \mathrm{F} / \mathrm{F}(\%)$ & SNR (puff) & Kinetics & Selectivity \\
\hline \multicolumn{6}{|l|}{ ACh sensors } \\
\hline $\mathrm{GRAB}_{\mathrm{ACh} 2.0}$ & $\mathrm{EC}_{50}=\sim 1-2 \mu \mathrm{m}$ & $\sim 90$ & $\sim 14$ & $\tau_{\text {on }}=\sim 250 \mathrm{~ms} ; \tau_{\text {off }}=\sim 700 \mathrm{~ms}$ & High \\
\hline $\mathrm{GRAB}_{\mathrm{ACh} 3.0}$ & $\mathrm{EC}_{50}=\sim 2 \mu \mathrm{m}$ & $\sim 280$ & - & $\tau_{\text {on }}=\sim 100 \mathrm{~ms} ; \tau_{\text {off }}=\sim 900 \mathrm{~ms}$ & High \\
\hline \multicolumn{6}{|l|}{ NE sensors } \\
\hline $\mathrm{GRAB}_{\text {NE1m }}$ & $\mathrm{EC}_{50}=\sim 2 \mu \mathrm{m}$ & $\sim 230$ & $\sim 75$ & $\tau_{\text {on }}=\sim 70 \mathrm{~ms} ; \tau_{\text {off }}=\sim 700 \mathrm{~ms}$ & $\mathrm{EC}_{50}=\sim 1400 \mu \mathrm{m}(\mathrm{DA})$ \\
\hline $\mathrm{GRAB}_{\mathrm{NE} 1 \mathrm{~h}}$ & $\mathrm{EC}_{50}=\sim 0.1 \mu \mathrm{m}$ & $\sim 130$ & $\sim 10$ & $\tau_{\text {on }}=\sim 35 \mathrm{~ms} ; \tau_{\text {off }}=\sim 2000 \mathrm{~ms}$ & $\mathrm{EC}_{50}=\sim 0.6 \mu \mathrm{m}(\mathrm{DA})$ \\
\hline $\mathrm{GRAB}_{5 \mathrm{HT} 1.0}$ & $\mathrm{EC}_{50}=\sim 0.02 \mu \mathrm{M}$ & $\sim 250$ & - & $\tau_{\text {on }}=\sim 200 \mathrm{~ms} ; \tau_{\text {off }}=\sim 3000 \mathrm{~ms}$ & High \\
\hline iSeroSnFR & $\begin{array}{l}\mathrm{EC}_{50}=\sim 1.5 \mu \mathrm{M} \\
K_{\mathrm{d}}=\sim 350 \mu \mathrm{M}\end{array}$ & $\sim 1000$ & - & $\tau_{\text {fast }}=\sim 4 \mathrm{~ms} ; \tau_{\text {slow }}=\sim 100 \mathrm{~ms}$ & High \\
\hline \multicolumn{6}{|l|}{ DA sensors } \\
\hline $\mathrm{GRAB}_{\mathrm{DA} 1 \mathrm{~m}}$ & $\mathrm{EC}_{50}=\sim 0.13 \mu \mathrm{m}$ & $\sim 90$ & - & $\tau_{\text {on }}=\sim 60 \mathrm{~ms} ; \tau_{\text {off }}=\sim 700 \mathrm{~ms}$ & $\mathrm{EC}_{50}=\sim 1.5 \mu \mathrm{m}$ (NE) \\
\hline $\mathrm{GRAB}_{\mathrm{DA} \mathrm{h}}$ & $\mathrm{EC}_{50}=\sim 0.01 \mu \mathrm{M}$ & $\sim 90$ & - & $\tau_{\text {on }}=\sim 140 \mathrm{~ms} ; \tau_{\text {off }}=\sim 2500 \mathrm{~ms}$ & $\mathrm{EC}_{50}=\sim 0.1 \mu \mathrm{m}$ (NE) \\
\hline dLight $_{1.1 / 1.2}$ & $K_{\mathrm{d}}=\sim 0.3-0.7 \mu \mathrm{M}$ & $\sim 300$ & - & $\tau_{\text {on }}=\sim 10 \mathrm{~ms} ; \tau_{\text {off }}=\sim 100 \mathrm{~ms}$ & $K_{\mathrm{d}}=\sim 20 \mu \mathrm{m}$ (NE) \\
\hline dLight $_{1.3}$ & $K_{\mathrm{d}}=\sim 2.0 \mu \mathrm{m}$ & $\sim 900$ & - & - & - \\
\hline RdLight $_{1}$ & $K_{\mathrm{d}}=\sim 2.0 \mu \mathrm{M}$ & $\sim 250$ & - & $\tau_{\text {on }}=\sim 15 \mathrm{~ms} ; \tau_{\text {off }}=\sim 400 \mathrm{~ms}$ & $K_{\mathrm{d}}=\sim 20-100 \mu \mathrm{m}(\mathrm{NE})$ \\
\hline
\end{tabular}

${ }^{a}$ Sensors with the highest SNR and fastest kinetics provide the best spatial and temporal resolutions critical for resolving synaptic properties of neuromodulatory transmission. For the sensors without SNR measurements, those with the sensitivity comparable to the concentration of endogenous neuromodulators (which offers the optimal baseline fluorescence and SNR) and highest $\Delta \mathrm{F} / \mathrm{F}$ might perform best.

transmitter binding (Fig. 1A). Two major groups of genetically encoded transmitter sensors have been created: $G$ proteincoupled receptor (GPCR)- and bacterial periplasmic binding protein $(\mathrm{PBP})$-based sensors.

GPCR-based sensors are typically engineered by replacing the third intracellular loop of G-protein-coupled ACh and monoamine receptors with a cpGFP. Evolution has tuned GPCRs to have appropriate affinity for detecting cognate molecules. GPCR-based sensors, which typically preserve the affinity, usually yield the balanced baseline and signal-evoked fluorescence best for imaging experiments. Moreover, GPCR-based sensors frequently inherit excellent membrane surface trafficking and pharmacological properties from primogenitor GPCRs (Wang et al., 2018; Andreoni et al., 2019); and researchers have taken advantage of the pharmacology to verify the specificity of recorded fluorescence responses (Jing et al., 2018; Piatkevich et al., 2018; Sun et al., 2018; Feng et al., 2019; Wan et al., 2020). Engineering GPCR-based sensors with large dynamic ranges and fast kinetics is crucial for effectively monitoring endogenous signals, but this can sometimes be challenging because of the primogenitors' slow kinetics and limited conformational changes associated with ligand binding (Wang et al., 2018; Andreoni et al., 2019).

PBPs belong to a diverse superfamily of proteins that recognize a plethora of small molecules, including ACh and monoamines (Dwyer and Hellinga, 2004). Since PBPs have evolved to help microbes navigate nutrient gradients and frequently have lower affinities, creating the PBP-based sensors with sensitivity matching the endogenous transmitter levels can be a daunting task (Marvin et al., 2013; Helassa et al., 2018). Because PBPs are soluble proteins, they are amenable to targeted expression in other subcellular compartments, albeit their membrane surface trafficking may require improvement. Fast kinetics and large dynamic ranges are the main advantages of PBP-based sensors, which could be vital for detecting fast dynamics of transmission. Finally, because PBP-based sensors are orthogonal to (or unaffected by) most cholinergic and monoaminergic drugs, they are compatible with certain pharmacological studies, such as drug screening (Shivange et al., 2019; Unger et al., 2020).

Although creating top-performing GPCR- and PBP-based sensors typically requires generations of evolution, this task has become less arduous with improved molecular evolution approaches, including machine-learning-guided protein redesign and directed evolution, and automated screening and analysis (Piatkevich et al., 2018; Villette et al., 2019). The improved molecular evolution approaches certainly accelerate the expansion of sensor toolbox (Table 1).

\section{ACh sensors}

Jing et al. (2018) reported the first family of user-friendly and broadly applicable genetically encoded GPCR activation-based ACh $\left(\mathrm{GRAB}_{\mathrm{ACh}}\right)$ sensors by incorporating cpGFP into the third intracellular loop of human muscarinic receptors, which minimizes downstream $G$ protein- and $\beta$-arrestin-coupled signaling (Wang et al., 2018). The same strategy has worked well in engineering GPCR-based sensors for DA, NE, and 5HT (Sun et al., 2018; Feng et al., 2019; Wan et al., 2020), indicating a generalizable approach. A more recently reported $\mathrm{GRAB}_{\mathrm{ACh} 3.0}$ sensor had a fluorescence response $\Delta \mathrm{F} / \mathrm{F} \sim 180 \%$ larger than that of previous versions, which enhanced its ability to detect miniscule cholinergic signals (Jing et al., 2020).

Borden et al. (2020) created the other family of genetically encoded ACh sensors, iAChSnFRs, based on a bacterial cholinebinding protein. cpGFP was inserted into the choline-binding protein at positions determined by quantitative structural analysis of local conformational changes induced by ligand binding, the same strategy developed for engineering iGluSnFRs (Marvin et al., 2013, 2018). Both green and yellow fluorescent versions of these sensors are available, and the latter is ideal for two-photon imaging.

Parameters of GPCR- and PBP-based sensors, often obtained under different experimental conditions in different laboratories, may not be comparable (Table 1). Experiments examining endogenous cholinergic transmission in the same medial entorhinal 
cortical preparation with both $\mathrm{GRAB}_{\mathrm{ACh}}$ and $\mathrm{iAChSnFR}$ sensors provided a direct comparison and revealed key differences between these two families of sensors (Borden et al., 2020; Zhu et al., 2020). $\mathrm{GRAB}_{\mathrm{ACh}}$ sensors produced large fluorescence responses, yet their inherited slow kinetics prevented them from faithfully following high-frequency cholinergic signals (Jing et al., $2018,2020)$. On the other hand, the slow kinetics of $\mathrm{GRAB}_{\mathrm{ACh}}$ sensors might integrate ACh signals over time. This property, together with their large fluorescence responses, could make them excellent somewhat all-or-none-like binary signal detectors. iAChSnFRs rivaled $\mathrm{GRAB}_{\mathrm{ACh} 2.0}$ in detecting low-frequency cholinergic signals, but surpassed $\mathrm{GRAB}_{\mathrm{ACh} 2.0}$ in following high-frequency cholinergic signals (e.g., see Borden et al., 2020, their Fig. S25). Moreover, iAChSnFRs had a large response dynamic range, allowing further improvement of fluorescence response (Borden et al., 2020). Notably, iAChSnFRs exhibited sufficient spatial and temporal resolution to allow characterization of fundamental synaptic properties of cholinergic transmission, including transmitter diffusion extent, number of release sites, release pool size, release probability, quantal size, and refilling rate, in various preparations (Borden et al., 2020; Lin et al., 2021; Zhu et al., 2020).

\section{NE sensors}

Using the same strategy that created $\mathrm{GRAB}_{\mathrm{ACh}}$ sensors, Feng et al. (2019) engineered a family of $\mathrm{GRAB}_{\mathrm{NE}}$ sensors for $\mathrm{NE}, \mathrm{GRAB}_{\mathrm{NE} 1 \mathrm{~m}}$, and $\mathrm{GRAB}_{\mathrm{NE} 1 \mathrm{~h}}$. Overall, $\mathrm{GRAB}_{\mathrm{NE} 1 \mathrm{~m}}$ performed better in monitoring endogenous adrenergic signals, yielding larger responses and following signals more faithfully because of its larger florescence responses, faster kinetics, and better specificity (Table 1 ). A GRAB ${ }_{\mathrm{NE} 1 \mathrm{~m}}$ minor variant, sometimes dubbed "GRAB ${ }_{\mathrm{NE} 2 \mathrm{~m}}$ " by researchers, has almost identical properties and performance compared with $\mathrm{GRAB}_{\mathrm{NE} 1 \mathrm{~m}}$ (Kwak et al., 2020). A few experiments compared performance of $\mathrm{iAChSnFR}$ and $\mathrm{GRAB}_{\mathrm{NE} 1 \mathrm{~m}}$ in monitoring endogenous cholinergic and adrenergic transmission in the same amygdalar preparation (Zhu et al., 2020). While GRAB NE1m $_{\text {performed worse }}$ than iAChSnFR in speed and fluorescence response, the sensor was able to follow the slower adrenergic signals (Zhu et al., 2020), raising the hope that $\mathrm{GRAB}_{\mathrm{NE} 1 \mathrm{~m}}$ may at least resolve some synaptic features of adrenergic transmission, although the experiments could be challenging because of the small fluorescence response.

\section{HT sensors}

In addition to $\mathrm{GRAB}_{\mathrm{ACh}}$ and $\mathrm{GRAB}_{\mathrm{NE}}$ sensors, Wan et al. (2020) recently introduced a family of $\mathrm{GRAB}_{5 \mathrm{HT}}$ sensors that are highly selective for $5 \mathrm{HT}$. Both GRAB ${ }_{5 \mathrm{HT} .5}$ and $\mathrm{GRAB}_{5 \mathrm{HT} 1.0}$ effectively detected endogenous serotonergic signals in populations of cells, yet $\mathrm{GRAB}_{5 \mathrm{HT} 0.5}$ appeared to perform better in detecting serotonergic signals at the single-cell and subcellular levels (Wan et al., 2020; Zhu et al., 2020), presumably because its kinetics and affinity match more closely to the dynamics and concentration of endogenously released 5HT (Table 1). The results also showed that $\mathrm{GRAB}_{5 \mathrm{HT} 0.5}$ served as an excellent tool to dissect fundamental synaptic properties of serotonergic transmission (Zhu et al., 2020).

Guided by a machine-learning-based binding-pocket redesign strategy, Unger et al. (2020) recently converted an early version of iAChSnFR into an iSeroSnFR sensor for 5HT (Table 1). iSeroSnFR reported robust endogenous serotonergic signals in populations of cells (Unger et al., 2020); yet given its low sensitivity, it will be important to see whether the sensor can detect single-cell and subcellular serotonergic transmission.

\section{DA sensors}

The Sun and Patriarchi teams independently developed two families of GPCR-based DA sensors: (1) GRAB ${ }_{\mathrm{DA}}$, based on human $\mathrm{D}_{2}$ dopamine receptors (Sun et al., 2018); and (2) dLight, based on human $\mathrm{D}_{1}$ dopamine receptors (Patriarchi et al., 2018, 2019) (Table 1). More recently, Sun et al. (2020) reported the second generation of $\mathrm{GRAB}_{\mathrm{DA}}$ sensors (Table 1). Compared with $\mathrm{GRAB}_{\mathrm{DA} 1 \mathrm{~m}}$ and $\mathrm{GRAB}_{\mathrm{DA} 1 \mathrm{~h}}$, the new green versions of $\mathrm{GRAB}_{\mathrm{DA} 2 \mathrm{~m}}$ and $\mathrm{GRAB}_{\mathrm{DA} 2 \mathrm{~h}}$ have significantly improved $\Delta F / F$, whereas the first red versions of $\mathrm{rGRAB}_{\mathrm{DA} 1 \mathrm{~m}}$ and $\mathrm{rGRAB}_{\mathrm{DA} 1 \mathrm{~h}}$ have slightly improved $\Delta \mathrm{F} / \mathrm{F}$. Likewise, the Tian team (Patriarchi et al., 2020) reported a red version DA sensor, RdLight ${ }_{1}$, which had similar $\Delta \mathrm{F} / \mathrm{F}$ compared with green dLight sensors (Table 1). All other properties of these new DA sensors remain largely unchanged (Patriarchi et al., 2020; Sun et al., 2020).

Direct experimental comparison showed that $\mathrm{GRAB}_{\mathrm{DA} 2 \mathrm{~m}}$ produced slightly larger single-cell dopaminergic responses with a better SNR compared with dLight ${ }_{1}$ in the striatum (Sun et al., 2020; Zhu et al., 2020). Given the extremely low baseline dLight ${ }_{1}$ fluorescence that frequently precluded identification of individual expressing cells, $\mathrm{GRAB}_{\mathrm{DA} 2 \mathrm{~m}}$ was handier in analyzing singlecell dopaminergic signals. On the other hand, dLight ${ }_{1}$ appears to have slightly higher selectivity for DA over NE than GRAB $_{\mathrm{DA} 2 \mathrm{~m}}$ (Table 1). GRAB $B_{D A}$ and dLight both worked well in observing dopaminergic signals from populations of cells in the striatum, which receives the heaviest dopaminergic innervations and probably largest dopaminergic signals (Bjorklund and Dunnett, 2007; Morales and Margolis, 2017). It waits additional experimentation to determine whether $\mathrm{GRAB}_{\mathrm{DA}}$ and dLight are capable of detecting modest single-cell dopaminergic signals in other brain areas, such as the PFC and hippocampus.

\section{Practical considerations}

The majority of genetically encoded neuromodulatory transmitter sensors seem to work well in various tissue preparations. A few top-performing sensors (e.g., iAChSnFR, GRAB ${ }_{\mathrm{NE} 1 \mathrm{~m}}$, and $\mathrm{GRAB}_{5 \mathrm{HT0.5}}$ ) detected robust but variable single-cell responses in every ex vivo and in vivo neuronal and non-neuronal tissues examined (Feng et al., 2019; Borden et al., 2020; Wan et al., 2020; Zhu et al., 2020), supporting their applicability in general tissue preparations. Genetically encoded DA sensors could detect single-cell dopaminergic responses in the striatum ex vivo and in vivo (compare Patriarchi et al., 2018; Sun et al., 2018, 2020; Zhu et al., 2020), but their efficacy in other brain areas remains unknown.

Genetically encoded sensors are powerful tools for resolving synaptic properties of neuromodulatory transmission if properly used. Because genetically encoded sensors perform better than the previously available monitoring tools in terms of fluorescence response and targeted expression, many laboratories have already combined them with imaging approaches (e.g., photometry) to monitor cholinergic and monoaminergic signals, as advocated by recent reviews (Wang et al., 2018; Andreoni et al., 2019; Jing et al., 2019; Sabatini and Tian, 2020). However, the top-performing genetically encoded sensors possess properties that empower them to do more. In addition to being able to follow rapid transmitter signals, fortuitously and welcomingly, these sensors emit a large amount of photons upon binding of neuromodulators, and their fluorescence responses are largely independent of expression levels (Feng et al., 2019; Borden et al., 2020; Wan et al., 2020; Zhu et al., 2020). These properties, when combined with superresolution and/or deconvolution 
microscopic analysis algorithms, permit dissection of the fundamental synaptic properties of neuromodulatory transmission, such as the transmitter diffusion extent, number of release sites, release pool size, release probability, quantal size, and refilling rate (Neher, 2015; Pulido and Marty, 2017). These synaptic parameters, which are essential for determining the mechanisms underlying behaviors (Henley and Wilkinson, 2016; Sudhof, 2018), could not be extracted effectively by electrophysiological recordings because neuromodulators typically produce only small and rapidly desensitizing neuromodulatory current responses (Dani and Bertrand, 2007; Nadim and Bucher, 2014). By determining these synaptic parameters, it should be possible to investigate the regulation, adaption (i.e., short- and long-term plasticity), and function of neuromodulatory transmission. Moreover, after defining the normal baseline, analyzing synaptic alterations of synapse-, subcellular-, and circuit-specific signals under disease conditions should shed new light on the neuromodulatory pathogenesis of a variety of diseases (Barbour and Hausser, 1997; Eban-Rothschild et al., 2018; Mohebi et al., 2019; Okaty et al., 2019).

Good experimental practice is essential for high spatiotemporal resolution imaging that is required to resolve synaptic properties of neuromodulatory transmission. Our experience with genetically encoded sensors highlights the importance of (1) mitigation and correction for image drift and fluctuations; (2) minimization of photobleaching, autofluorescence, and noise; and (3) optimization of light diffraction correction. Adapting stable recording systems, such as electrophysiological setups designed for ex vivo and in vivo multiple patch-clamp recordings (Zhu, 2009; Jiang et al., 2013; Zhang et al., 2018), can mitigate experimental drifts and fluctuation, and thus allow acquisition of stable livingcell images easily correctable with an intensity-based registration function (Wang et al., 2015a; Zhu et al., 2020). Running optimized correction algorithms can minimize photobleaching, autofluorescence, and noise (Zhu et al., 2020). Getting the accurate point spread function and using optimized analysis algorithms are vital for reversing optical diffraction to "reassign" the light to its original place (Sibarita, 2005; Guo et al., 2020).

Our experiments have shown that iAChSnFR, GRAB ${ }_{\mathrm{NE} 1 \mathrm{~m}}$, and $\mathrm{GRAB}_{5 \mathrm{HT} .5}$ have the essential qualities required for high spatiotemporal resolution image analysis of endogenously released neuromodulators, and they can resolve synaptic properties of neuromodulatory transmission (Feng et al., 2019; Borden et al., 2020; Wan et al., 2020; Zhu et al., 2020); but the performance of several other sensors requires further evaluation. Fortunately, all genetically encoded neuromodulatory transmitter sensors come from a few rigorous research groups. Thus, one may roughly deduce the relative performance of sensors generated from the same groups based on their reported sensor specificities (e.g., sensitivity, $\Delta \mathrm{F} / \mathrm{F}, \mathrm{SNR}$, and kinetics) (Table 1).

Various expression methods have helped in the engineering, validation, and application of genetically encoded transmitter sensors (Fig. 1B). Transfection provides a quick and convenient method for expression as genetically encoded sensors are being developed. Transfected cultured non-neuronal cells and neurons are perfect for quickly screening and rating properties of genetically encoded sensor variants. However, the best-performing sensor variants in cultured cells may not be the top performers in tissue slice and intact brain preparations. Therefore, viral expression in ex vivo and in vivo preparations is indispensable for screening and ranking the best-performing sensor variants, and subsequently validating their application. Three viral expression systems, including adeno-associated virus (AAV), lenti, and Sindbis viruses, are routinely used in screening and validating genetically encoded sensors. Several serotypes of AAV viruses have been extensively used because of their minimal toxicity, persistent expression ( $\geq 6$ months), and possibility for noninvasive delivery (Samulski and Muzyczka, 2014; Wang et al., 2019); these features are particularly suitable for long-term physiological and behavioral tests. However, the low viral production efficiency and slow expression time ( $\geq 3$ weeks) of AAV preclude its use in screening sensor variants, and the small payload for a transgene (up to $\sim 4.5-5 \mathrm{~kb}$ ) limits its applications in coexpression with other transgenes (Samulski and Muzyczka, 2014; Wang et al., 2019). Although the rapid serotypes of AAV viruses could drive expression within a week, they come with the price of increased cell toxicity (Jing et al., 2018). Lentiviruses have relatively faster production, shorter expression time ( $\sim 1-2$ weeks), and long-lived expression (multiple months) (Matrai et al., 2010; Alfranca et al., 2018), making them excellent choices in sensor screening and validation experiments. Lentiviruses allow expression of a transgene of up to $\sim 8-10 \mathrm{~kb}$ (Matrai et al., 2010; Lim et al., 2017; Alfranca et al., 2018), permitting coexpression with other transgenes and/or knockdown siRNAs. As with AAVs, modifications of envelope components, regulatory elements, and administration routes allow lentiviruses to achieve targeting expression in various types of cells and tissues (Borden et al., 2020; Zhu et al., 2020). Sindbis virus has the most efficient production time $(\sim 1.5 \mathrm{~d})$, shortest expression time $(\sim 8-16 \mathrm{~h})$, and highest expression levels (particularly for membrane proteins), but it has a relatively short viable expression time $(\sim 3-5 \mathrm{~d})$ (Malinow et al., 2010; Uyaniker et al., 2019). These characteristics make Sindbis virus perfect for rapid screening of potentially workable sensors and validation of their properties. We note that the Sindbis-driven high sensor expression can be particularly advantageous for less-than-optimal sensors (e.g., GRAB $\mathrm{BE}_{\mathrm{NE} 1 \mathrm{~m}}$ and dLight $_{1}$ ) to achieve high-resolution image analysis (Feng et al., 2019; Zhu et al., 2020). In addition, the large Sindbis payload of up to $15 \mathrm{~kb}$ enables combination with additional genetic and imaging applications (Wang et al., 2015b; Zhang et al., 2018). Although Sindbis has a strong neurotropism toward excitatory neurons, local administration permits expression in GABAergic interneurons and non-neuronal cells (Jing et al., 2018; Zhu et al., 2020). Importantly, viral expression can be used with cre mice to achieve more controllable expression of genetically encoded sensors (Borden et al., 2020; Unger et al., 2020). In addition, transgenic mice expressing genetically encoded neuromodulatory transmitter sensors are being created, which will add additional convenience to the sensors' applications.

\section{Biological applications}

A substantial number of recently published "proof-of-principle" tools or methods failed to work for biology because they were not rigorously validated (e.g., see Meister, 2016; Wang et al., 2020). Several genetically encoded neurotransmitter sensors have gone through rigorous validation that demonstrates their applicability in resolving a few fundamental biological questions (Jing et al., 2018; Borden et al., 2020; Zhu et al., 2020). For example, the new sensors delivered a direct answer to the long-standing neurobiological question of whether the primary neuromodulatory transmission mode is restricted or volume transmission (Barbour and Hausser, 1997; Sarter et al., 2009). The dominant theory for neuromodulatory transmission proposed three decades ago postulated that 
the primary mode of intercellular neuromodulatory communication is volume transmission among groups of cells within a region, rather than restricted transmission between specific cells that form direct circuits or contacts (Agnati et al., 1992; Zoli et al., 1999). Specifically, the volume transmission model purports that $\mathrm{ACh}$ and monoamines diffuse into local areas, affecting many different types of nearby cells, and that neuropeptides travel even farther, influencing both local cells and cells millimeters away (Agnati et al., 1992; Borroto-Escuela et al., 2018). However, this theory is based primarily on the postulation that endogenously released neuromodulatory transmitters behave similarly to exogenously applied ones (that diffuse more freely in the extrasynaptic space), an assumption that has not yet been corroborated by direct experimental evidence (Barbour and Hausser, 1997; Sarter et al., 2009). Because previous imaging techniques did not allow direct visualization of transmitter release and diffusion at individual release sites (Sykova and Nicholson, 2008; Zheng et al., 2017), some researchers had ingeniously used mathematical models to simulate the evoked releases. Although this approach could not distinguish single and multiple closely packed release sites, it gave decent estimations of neuromodulatory transmitter spread areas with radius of $\sim 5.0-10.0 \mu \mathrm{m}$ (Beckstead et al., 2004; Courtney and Ford, 2014, 2016). Unfortunately, these studies were underappreciated, due presumably to their indirect calculation approaches and/or their dependence on simulation assumptions. Genetically encoded neuromodulatory transmitter sensors, in combination with superresolution (Sauer, 2013; Li and Vaughan, 2018) and/or deconvolution (Arigovindan et al., 2013; Weigert et al., 2018) microscopic analysis strategies (Fig. 1C), permitted the first visualization of spatial diffusion of neuromodulatory transmitters at individual release sites (Fig. 1D). The analysis yielded precise diffusion spread length constants of $\sim 0.75 \mu \mathrm{m}$ for both ACh and monoamines (Zhu et al., 2020), with the cholinergic spread length constant independently verified in the intact brain (Borden et al., 2020). These results indicate that highly restricted, nonvolume neuromodulatory transmission is a key mode for intercellular communication.

The finding of restricted neuromodulatory transmission has multiple implications. Like several other transmission parameters, such as the amount of released transmitter, width of synaptic clefts, and location of postsynaptic transmitter receptors across various synapses (Savtchenko and Rusakov, 2007; Savtchenko et al., 2013; Haas et al., 2018), spatial spread length constants of neurotransmitters (i.e., glutamate, ACh, monoamines, and neuropeptides) are almost identical across various cell types (Lin et al., 2021; Zhu et al., 2020). These results support the idea that synapses optimize their nanoscale presynaptic and postsynaptic organizational elements to maximize efficacy and precision.

The restricted diffusion of released neuromodulators also indicates that neuromodulatory transmission resembles fast-acting glutamatergic and GABAergic transmission in fine spatial regulation. Interestingly, as with the fast-acting transmitters glutamate (e.g., via NMDA receptors) (Rusakov et al., 1999) and GABA (e.g., via $\delta$ subunit-containing $\mathrm{GABA}_{\mathrm{A}}$ receptors) (Brickley and Mody, 2012), neuromodulatory transmitters may likewise engage high-affinity receptors (Kellar et al., 1985; Dani and Bertrand, 2007) and/or large clusters of release sites to achieve certain volume transmission effects under physiological and pathologic conditions. Thus, the previous results, together with new imaging findings (Barbour and Hausser, 1997; Jensen et al., 2019; Zhu et al., 2020), support an emerging concept that a key mode of intercellular communication for both fast-acting (i.e., glutamate and GABA) and slow-acting neurotransmitters is highly restricted transmission, and this mode is complemented by volume transmission under certain conditions.

Some genetically encoded neurotransmitter sensors exhibit both fast kinetics and photostability that permit stable measurements of synaptic responses with high temporal resolution, providing an opportunity to improve quantitative understanding of neuromodulatory synaptic properties (Neher, 2015; Thanawala and Regehr, 2016). Traditionally, patch-clamp recordings, which make reliable measurements of excitatory and inhibitory currents after high-frequency activation, serve as the prime method to define synaptic properties of glutamatergic and GABAergic transmission (Elmqvist and Quastel, 1965; Schneggenburger et al., 1999; Ruiz et al., 2011; Thanawala and Regehr, 2013). However, small and rapidly desensitizing neuromodulatory currents make electrophysiology an ineffective approach to determine synaptic parameters of neuromodulatory transmission. Some genetically encoded transmitter sensors possess kinetics fast enough to follow slow neuromodulatory synaptic releases evoked by moderate (actually, more physiological) rates of stimulation over a prolonged period (Borden et al., 2020; Lin et al., 2021; Zhu et al., 2020). This should permit reasonably accurate estimation of neuromodulatory synaptic properties (e.g., number of release sites, release pool size, release probability, quantal size, and refilling rate) (Neher, 2015; Pulido and Marty, 2017). Our preliminary analysis indicated that neuromodulatory transmission at times acted very differently from classic fast glutamatergic and GABAergic transmission (Borden et al., 2020; Zhu et al., 2020), inspiring new ideas about neuromodulatory engagements in various behaviors and diseases (see Discussion below).

\section{Clinical applications in Alzheimer's disease, sleeping disorders, and tumorigenesis}

New insights into neuromodulatory transmission explain some perplexing clinical observations and suggest novel potential therapeutic interventions for various neurologic disorders, including Alzheimer's disease (Fig. 2). For example, the only available therapy for Alzheimer's disease is based on the finding of diminished ACh release and deteriorating cholinergic neurons in Alzheimer's brains: the cholinergic hypothesis (Mash et al., 1985). Currently, all FDA-approved Alzheimer's drugs directly or indirectly inhibit acetylcholinesterase (AChE) to boost cholinergic signals. These medicines have limited efficacy in cognitive improvement, and on medication termination, induce irreversible, accelerated deterioration (Zemek et al., 2014; Ashford, 2015). The unexpected fine regulation of cholinergic transmission illustrated by genetically encoded sensors sheds light on these two clinical observations (Borden et al., 2020; Zhu et al., 2020). First, AChE inhibitors might reduce the physiological precision of cholinergic transmission (Barbour and Hausser, 1997; Sarter et al., 2009), explaining the limited cognitive improvement. Second, long-term application of AChE inhibitors might homeostatically upregulate AChE levels in Alzheimer's patients and/or downregulate presynaptic ACh release (Ashford, 2015), explaining the accelerated deterioration upon medication termination.

Like disrupted cholinergic signaling, dysregulated adrenergic transmission also appears as an early pathologic correlate of cognitive decline in Alzheimer's disease (Mather and Harley, 2016; Simic et al., 2017). Genetically encoded sensors 
revealed unexpected adrenergic synaptic properties that seem to run counter to the natural tendency of synapses to achieve fine-tuned linear input-output computational processes (Zhu et al., 2020). These properties distinguish adrenergic transmission from all other neuronal transmission, including the fast glutamatergic and GABAergic transmission (Jackman and Regehr, 2017) as well as cholinergic and other monoaminergic transmissions (Zhu et al., 2020). The findings explain the unique involvement of adrenergic transmission in fine-tuning of attention (Carter et al., 2010), optimization of behavior in complex social and physical environments (Gompf et al., 2010), and deficits in complex mental processes (e.g., reasoning and abstract thinking) in Alzheimer's patients (McKhann et al., 2011). The new understanding of cholinergic and adrenergic transmission would immediately suggest multiple synaptic mechanisms as potentially effective targets for intervention and set the physiological transmission reference for future medication testing and development.

Genetically encoded sensors may help to solve the mystery of sleep, and such understanding should suggest effective treatments for sleep disorders. Sleep is one of the most mysterious yet ubiquitous animal behaviors, and sleep disorders are among the most common clinical problems, causing a number of health issues that range from cognitive and immune deficiencies to cardiovascular diseases and obesity (Weber and Dan, 2016; Scammell et al., 2017; Eban-Rothschild et al., 2018). Many factors modulate sleep-wake behaviors, but ACh and monoamines play complex and central roles (Fig. 2). While experimental data consistently show that cholinergic nuclei have important roles in initiating and maintaining wakefulness (Buzsaki et al., 1988; Fuller et al., 2011), existing evidence is inconclusive as to whether cholinergic neurons are necessary for wakefulness (Scammell et al., 2017; Eban-Rothschild et al., 2018). Genetically encoded ACh sensors illustrated that neuronal activity could induce large initial and small sustained ACh releases (Jing et al., 2018; Borden et al., 2020; Zhu et al., 2020), providing a biophysical base for cholinergic involvement in initiation and maintenance of wakefulness. It was proposed that combining optogenetic and chemogenetic techniques with new monitoring tools, which allow direct assessment of cholinergic releases at natural sleep-wake cycles (e.g., genetically encoded ACh sensors), might delineate the exact cholinergic contributions in sleep-wake behaviors (Scammell et al., 2017). Unlike the cholinergic nuclei, loss of locus coeruleus cells did not stop wakefulness but instead impaired wakefulness under socially and physically complex environments (Gompf et al., 2010). Visualization of adrenergic transmission with genetically encoded NE sensors illustrated that adrenergic synapses operated in a linear computational mode (Borden et al., 2020; Zhu et al., 2020), perfect for the possible adrenergic role of finely tuning wakefulness and attention (Carter et al., 2010). Making linear signal amplification, which runs against the natural tendency of synapses that weakens during activation (Jackman and Regehr, 2017), renders adrenergic transmission to be vulnerable to system runaway. To avoid such risk, adrenergic synapses seemed to set a small release pool and a tiny refill rate to ensure transmitter depletion after a certain amount of neuronal activity (Borden et al., 2020; Zhu et al., 2020), creating an emergency break point presumably responsible for the observed behavioral arrests (Carter et al., 2010). A comprehensive analysis of adrenergic synaptic properties with genetically encoded NE sensors should define adrenergic roles in sleep-wake cycles, and unveil the pathogenesis of behavioral arrests and sleep disorders.

Serotonergic and dopaminergic mechanisms in regulating sleep-wake cycles remain elusive. Early research suggested that 5HT might initiate and maintain sleep, whereas later work found that serotonergic neurons promoted wake fulness (Scammell et al., 2017; Eban-Rothschild et al., 2018). Because serotonergic signals regulate a variety of physiological processes, whether the observed serotonergic effects on sleep-wake cycles are original or secondary is still unclear. Genetically encoded $5 \mathrm{HT}$ sensors may connect synaptic dynamics of serotonergic transmission with specific sleep-wake events, and thus define the precise serotonergic roles in sleep-wake behaviors (Wan et al., 2020). Dopaminergic neurons act as key modulators of sleep and wakefulness. Sleep, like food, water, and sex, appears to serve as a primary reinforcer, and existing experimental data indicate that dopaminergic neuronal activity and extracellular DA levels correlate with circadian oscillations and sleep-orienting behaviors (Korshunov et al., 2017; Rial et al., 2018). However, whether and how DA regulates, and/or is regulated by, the circadian clock and other sleep-wake regulators remain mysterious because of modest and varied DA release changes in the midbrain, hypothalamus, and other related brain areas over the sleep-wake cycle. This underlines the significance of monitoring cell type- and projection-specific dopaminergic contributions to sleep-wake regulation (Scammell et al., 2017; Eban-Rothschild et al., 2018). Genetically encoded DA sensors have fast kinetics to track synaptic dopaminergic signals (Patriarchi et al., 2018; Sun et al., 2018, 2020) and permit 
visualization of dopaminergic transmission with the high spatial resolution (Zhu et al., 2020). Given the modest DA release associated with sleep-wake cycles (Eban-Rothschild et al., 2018), the next generation of DA sensors with improved fluorescence responses may aid synapse-, subcellular-, and circuitspecific dissection of dopaminergic contributions to sleepwake behaviors.

Genetically encoded sensors can advance understanding and treatment of cancer because recent studies recognize a major neuromodulatory contribution to cancer development and metastasis (Servick, 2019; Zahalka and Frenette, 2020), and revive an ancient idea that perineuronal invasion processes are central for tumor cells to gain access to migratory routes and prosurvival components (Ernst, 1905). In particular, there is now good evidence indicating that adrenergic fibers promote cancer cell survival during the initial stage of cancer development via adrenergic receptors, while cholinergic fibers contribute to later phases of cancer invasion (i.e., migration and metastases) (Magnon et al., 2013; Mauffrey et al., 2019). Similarly, dopaminergic and serotonergic inputs play a role in tumor proliferation and dissemination (Jiang et al., 2020). These findings rendered surgical or chemical denervation and pharmacological inhibition of neuromodulation promising antitumor therapeutic options. However, preclinical and clinical trials reported conflicting results of these treatments in controlling tumor development (Jiang et al., 2020; March et al., 2020), underscoring the need for decoding neuromodulatory roles in multiple biological behaviors of cancers, such as cancer cell survival, proliferation, resistance to apoptosis, invasion, metastasis, angiogenesis, and stromal cell transition in tumor initiation and progression. Recently developed genetically encoded neuromodulatory transmitter sensors provide viable tools for direct visualization of neuromodulatory communications among nerve, cancer, immune, and/or endothelial cells during tumor proliferation and dissemination. This line of research is likely to lead to better understanding of tumorigenesis and effective neuromodulation-based antitumor therapies.

In conclusion, the impressive amount of prior work on neuromodulation has underscored the importance of neuromodulatory transmission in various behaviors and diseases, yet our understanding of the regulation and properties of neuromodulatory transmission remains primitive because of limitations of available tools that can quantitatively analyze the transmission. Recently engineered genetically encoded neuromodulatory transmitter sensors power up our toolbox with a set of tools that allow quantification of synaptic parameters of neuromodulatory transmission. Because qualifying synaptic properties of neurotransmission is essential for understanding the physiology and pathology of behaviors and diseases (Bayes et al., 2011; Volk et al., 2015; Henley and Wilkinson, 2016; Sudhof, 2018), we expect these new sensors to rapidly change the landscape of neuromodulation research.

Indeed, initial experimental work validates that genetically encoded sensors, when combined with superresolution and deconvolution microscopic analysis, can decode the fundamental synaptic properties of neuromodulatory transmission (Borden et al., 2020; Lin et al., 2021; Zhu et al., 2020). It is important to note that both high-performing sensors and good practical solutions are critical for the success of biological applications (Lin et al., 2021; Zhu et al., 2020). We discussed how genetically encoded neuromodulatory transmitter sensors might advance our understanding of Alzheimer's disease, sleep-wake cycle and related sleep disorders, and tumorigenesis. The applications of genetically encoded sensors certainly do not stop here since $\mathrm{ACh}$ and monoamines play critical roles in a wide range of behaviors and diseases, including addiction, autism, cardiovascular regulation and diseases, mood disorders, schizophrenia, immune regulation and deficiency, metabolic regulation, and eating disorders (Fig. 2). Therefore, we expect that combining newly developed genetically encoded sensors with superresolution and deconvolution microscopic analysis algorithms will shed new light on the physiology or pathology of a large variety of behaviors and diseases.

\section{References}

Agnati LF, Bjelke B, Fuxe K (1992) Volume transmission in the brain. Am Sci 80:362-373.

Alfranca A, Campanero MR, Redondo JM (2018) New methods for disease modeling using lentiviral vectors. Trends Mol Med 24:825-837.

Andreoni A, Davis CM, Tian L (2019) Measuring brain chemistry using genetically encoded fluorescent sensors. Curr Opin Biomed Eng 12:59-67.

Arigovindan M, Fung JC, Elnatan D, Mennella V, Chan YH, Pollard M, Branlund E, Sedat JW, Agard DA (2013) High-resolution restoration of $3 \mathrm{D}$ structures from widefield images with extreme low signal-to-noise-ratio. Proc Natl Acad Sci USA 110:17344-17349.

Ashford JW (2015) Treatment of Alzheimer's disease: the legacy of the cholinergic hypothesis, neuroplasticity, and future directions. J Alzheimers Dis 47:149-156.

Aston-Jones G, Cohen JD (2005) An integrative theory of locus coeruleusnorepinephrine function: adaptive gain and optimal performance. Annu Rev Neurosci 28:403-450.

Ballinger EC, Ananth M, Talmage DA, Role LW (2016) Basal forebrain cholinergic circuits and signaling in cognition and cognitive decline. Neuron 91:1199-1218.

Barbour B, Hausser M (1997) Intersynaptic diffusion of neurotransmitter. Trends Neurosci 20:377-384.

Bayes A, van de Lagemaat LN, Collins MO, Croning MD, Whittle IR, Choudhary JS, Grant SG (2011) Characterization of the proteome, diseases and evolution of the human postsynaptic density. Nat Neurosci 14:19-21.

Beckstead MJ, Grandy DK, Wickman K, Williams JT (2004) Vesicular dopamine release elicits an inhibitory postsynaptic current in midbrain dopamine neurons. Neuron 42:939-946.

Berger M, Gray JA, Roth BL (2009) The expanded biology of serotonin. Annu Rev Med 60:355-366.

Berridge CW, Schmeichel BE, Espana RA (2012) Noradrenergic modulation of wakefulness/arousal. Sleep Med Rev 16:187-197.

Bjorklund A, Dunnett SB (2007) Dopamine neuron systems in the brain: an update. Trends Neurosci 30:194-202.

Borden PM, Zhang P, Shivange AV, Marvin JS, Cichon J, Dan C, Podgorski K, Figueiredo A, Novak O, Tanimoto M, Shigetomi E, Lobas MA, Kim H, Zhu PK, Zhang Y, Zheng WS, Fan CC, Wang G, Xiang B, Li G, et al. (2020) A fast genetically encoded fluorescent sensor for faithful in vivo acetylcholine detection in mice, fish, worms and flies. bioRxiv. doi: 10.1101/2020.02.07.939504.

Borroto-Escuela DO, Perez De La Mora M, Manger P, Narváez M, Beggiato S, Crespo-Ramírez M, Navarro G, Wydra K, Díaz-Cabiale Z, Rivera A, Ferraro L, Tanganelli S, Filip M, Franco R, Fuxe K (2018) Brain dopamine transmission in health and Parkinson's disease: modulation of synaptic transmission and plasticity through volume transmission and dopamine heteroreceptors. Front Synaptic Neurosci 10:20.

Brickley SG, Mody I (2012) Extrasynaptic GABA $A_{A}$ receptors: their function in the CNS and implications for disease. Neuron 73:23-34.

Buzsaki G, Bickford RG, Ponomareff G, Thal LJ, Mandel R, Gage FH (1988) Nucleus basalis and thalamic control of neocortical activity in the freely moving rat. J Neurosci 8:4007-4026.

Carter ME, Yizhar O, Chikahisa S, Nguyen H, Adamantidis A, Nishino S, Deisseroth K, de Lecea L (2010) Tuning arousal with optogenetic modulation of locus coeruleus neurons. Nat Neurosci 13:1526-1533.

Courtney NA, Ford CP (2014) The timing of dopamine- and noradrenalinemediated transmission reflects underlying differences in the extent of spillover and pooling. J Neurosci 34:7645-7656. 
Courtney NA, Ford CP (2016) Mechanisms of 5-HT1A receptor-mediated transmission in dorsal raphe serotonin neurons. J Physiol 594:953-965.

Dani JA, Bertrand D (2007) Nicotinic acetylcholine receptors and nicotinic cholinergic mechanisms of the central nervous system. Annu Rev Pharmacol Toxicol 47:699-729.

Dantzer R (2018) Neuroimmune interactions: from the brain to the immune system and vice versa. Physiol Rev 98:477-504.

Darvesh AS, Carroll RT, Geldenhuys WJ, Gudelsky GA, Klein J, Meshul CK, Van der Schyf CJ (2011) In vivo brain microdialysis: advances in neuropsychopharmacology and drug discovery. Expert Opin Drug Discov 6:109-127.

Dayan P, Huys QJ (2009) Serotonin in affective control. Annu Rev Neurosci 32:95-126.

Dwyer MA, Hellinga HW (2004) Periplasmic binding proteins: a versatile superfamily for protein engineering. Curr Opin Struct Biol 14:495-504.

Eban-Rothschild A, Appelbaum L, de Lecea L (2018) Neuronal mechanisms for sleep/wake regulation and modulatory drive. Neuropsychopharmacology 43:937-952.

Elmqvist D, Quastel DM (1965) A quantitative study of end-plate potentials in isolated human muscle. J Physiol 178:505-529.

Ernst P (1905) Uber das Wachstum und die Verbreitung Bostariger eshwulste insbesondere des Krebes in den Lymphbahnen der Nerven. Beitr Pathol Anat 7:1905.

Feng J, Zhang C, Lischinsky JE, Jing M, Zhou J, Wang H, Zhang Y, Dong A, Wu Z, Wu H, Chen W, Zhang P, Zou J, Hires SA, Zhu JJ, Cui G, Lin D, Du J, Li Y (2019) A genetically encoded fluorescent sensor for rapid and specific in vivo detection of norepinephrine. Neuron 102:745-761.e748.

Fuller PM, Fuller P, Sherman D, Pedersen NP, Saper CB, Lu J (2011) Reassessment of the structural basis of the ascending arousal system. J Comp Neurol 519:933-956.

Gompf HS, Mathai C, Fuller PM, Wood DA, Pedersen NP, Saper CB, Lu J (2010) Locus ceruleus and anterior cingulate cortex sustain wakefulness in a novel environment. J Neurosci 30:14543-14551.

Grace AA (2016) Dysregulation of the dopamine system in the pathophysiology of schizophrenia and depression. Nat Rev Neurosci 17:524-532.

Guo M, Li Y, Su Y, Lambert T, Nogare DD, Moyle MW, Duncan LH, Ikegami R, Santella A, Rey-Suarez I, Green D, Beiriger A, Chen J, Vishwasrao H, Ganesan S, Prince V, Waters JC, Annunziata CM, Hafner M, Mohler WA, et al. (2020) Rapid image deconvolution and multiview fusion for optical microscopy. Nat Biotechnol 38:1337-1346.

Haas KT, Compans B, Letellier M, Bartol TM, Grillo-Bosch D, Sejnowski TJ, Sainlos M, Choquet D, Thoumine O, Hosy E (2018) Pre-post synaptic alignment through neuroligin-1 tunes synaptic transmission efficiency. eLife 7:e31755.

Helassa N, Durst CD, Coates C, Kerruth S, Arif U, Schulze C, Wiegert JS, Geeves M, Oertner TG, Torok K (2018) Ultrafast glutamate sensors resolve high-frequency release at Schaffer collateral synapses. Proc Natl Acad Sci USA 115:5594-5599.

Henley JM, Wilkinson KA (2016) Synaptic AMPA receptor composition in development, plasticity and disease. Nat Rev Neurosci 17:337-350.

Herring N, Kalla M, Paterson DJ (2019) The autonomic nervous system and cardiac arrhythmias: current concepts and emerging therapies. Nat Rev Cardiol 16:707-726.

Hu HL (2016) Reward and aversion. Annu Rev Neurosci 39:297-324.

Jackman SL, Regehr WG (2017) The mechanisms and functions of synaptic facilitation. Neuron 94:447-464.

Jacob SN, Nienborg H (2018) Monoaminergic neuromodulation of sensory processing. Front Neural Circuits 12:51.

Jacobs BL, Azmitia EC (1992) Structure and function of the brain serotonin system. Physiol Rev 72:165-229.

Jensen TP, Zheng K, Cole N, Marvin JS, Looger LL, Rusakov DA (2019) Multiplex imaging relates quantal glutamate release to presynaptic $\mathrm{Ca}^{2+}$ homeostasis at multiple synapses in situ. Nat Commun 10:1414.

Jiang SH, Hu LP, Wang X, Li J, Zhang ZG (2020) Neurotransmitters: emerging targets in cancer. Oncogene 39:503-515.

Jiang X, Wang G, Lee AJ, Stornetta RL, Zhu JJ (2013) The organization of two new cortical interneuronal circuits. Nat Neurosci 16:210-218.

Jing M, Zhang P, Wang G, Feng J, Mesik L, Zeng J, Jiang H, Wang S, Looby JC, Guagliardo NA, Langma LW, Lu J, Zuo Y, Talmage DA, Role LW, Barrett PQ, Zhang LI, Luo M, Song Y, Zhu JJ, et al. (2018) A genetically encoded fluorescent acetylcholine indicator for in vitro and in vivo studies. Nat Biotechnol 36:726-737.
Jing M, Zhang Y, Wang H, Li Y (2019) G-protein-coupled receptor-based sensors for imaging neurochemicals with high sensitivity and specificity. J Neurochem 151:279-288.

Jing M, Li Y, Zeng J, Huang P, Skirzewski M, Kljakic O, Peng W, Qian T, Tan K, Zou J, Trinh S, Wu R, Zhang S, Pan S, Hires SA, Xu M, Li H, Saksida LM, Prado VF, Bussey TJ, et al. (2020) An optimized acetylcholine sensor for monitoring in vivo cholinergic activity. Nat Methods 17:1139-1146.

Kellar KJ, Martino AM, Hall DP Jr, Schwartz RD, Taylor RL (1985) High-affinity binding of $\left[{ }^{3} \mathrm{H}\right]$ acetylcholine to muscarinic cholinergic receptors. J Neurosci 5:1577-1582.

Korshunov KS, Blakemore LJ, Trombley PQ (2017) Dopamine: a modulator of circadian rhythms in the central nervous system. Front Cell Neurosci 11:91.

Kruse AC, Kobilka BK, Gautam D, Sexton PM, Christopoulos A, Wess J (2014) Muscarinic acetylcholine receptors: novel opportunities for drug development. Nat Rev Drug Discov 13:549-560.

Kwak H, Koh W, Kim S, Song K, Shin JI, Lee JM, Lee EH, Bae JY, Ha GE, Oh JE, Park YM, Kim S, Feng J, Lee SE, Choi JW, Kim KH, Kim YS, Woo J, Lee D, Son T, et al. (2020) Astrocytes control sensory acuity via tonic inhibition in the thalamus. Neuron 108:691-706.e610.

Li H, Vaughan JC (2018) Switchable fluorophores for single-molecule localization microscopy. Chem Rev 118:9412-9454.

Lim CS, Kang X, Mirabella V, Zhang H, Bu Q, Araki Y, Hoang ET, Wang S, Shen Y, Choi S, Kaang BK, Chang Q, Pang ZP, Huganir RL, Zhu JJ (2017) BRaf signaling principles unveiled by large-scale human mutation analysis with a rapid lentivirus-based gene replacement method. Genes Dev 31:537-552.

Lin L, Gupta S, Zheng WS, Si K, Zhu JJ (2021) Genetically encoded sensors enable micro- and nano-scopic decoding of transmissions in healthy and diseased brains. Mol Psychiatry 26:443-455.

Lin MZ, Schnitzer MJ (2016) Genetically encoded indicators of neuronal activity. Nature neuroscience 19:1142-1153.

Magnon C, Hall SJ, Lin J, Xue X, Gerber L, Freedland SJ, Frenette PS (2013) Autonomic nerve development contributes to prostate cancer progression. Science 341:1236361.

Maia TV, Frank MJ (2011) From reinforcement learning models to psychiatric and neurological disorders. Nat Neurosci 14:154-162.

Malinow R, Hayashi Y, Maletic-Savatic M, Zaman SH, Poncer JC, Shi SH, Esteban JA, Osten P, Seidenman K (2010) Introduction of green fluorescent protein (GFP) into hippocampal neurons through viral infection. Cold Spring Harb Protoc 2010:pdb.prot5406.

March B, Faulkner S, Jobling P, Steigler A, Blatt A, Denham J, Hondermarck $\mathrm{H}$ (2020) Tumour innervation and neurosignalling in prostate cancer. Nat Rev Urol 17:119-130.

Marvin JS, Borghuis BG, Tian L, Cichon J, Harnett MT, Akerboom J, Gordus A, Renninger SL, Chen TW, Bargmann CI, Orger MB, Schreiter ER, Demb JB, Gan WB, Hires SA, Looger LL (2013) An optimized fluorescent probe for visualizing glutamate neurotransmission. Nat Methods 10:162170

Marvin JS, Scholl B, Wilson DE, Podgorski K, Kazemipour A, Müller JA, Schoch S, Quiroz FJ, Rebola N, Bao H, Little JP, Tkachuk AN, Cai E, Hantman AW, Wang SS, DePiero VJ, Borghuis BG, Chapman ER, Dietrich D, DiGregorio DA, et al. (2018) Stability, affinity, and chromatic variants of the glutamate sensor iGluSnFR. Nat Methods 15:936-939.

Mash DC, Flynn DD, Potter LT (1985) Loss of $\mathrm{M}_{2}$ muscarine receptors in the cerebral cortex in Alzheimer's disease and experimental cholinergic denervation. Science 228:1115-1117.

Mather M, Harley CW (2016) The locus coeruleus: essential for maintaining cognitive function and the aging brain. Trends Cogn Sci 20:214-226.

Matrai J, Chuah MK, VandenDriessche T (2010) Recent advances in lentiviral vector development and applications. Mol Ther 18:477-490.

Mauffrey P, Tchitchek N, Barroca V, Bemelmans AP, Firlej V, Allory Y, Romeo PH, Magnon C (2019) Progenitors from the central nervous system drive neurogenesis in cancer. Nature 569:672-678.

McKhann GM, Knopman DS, Chertkow H, Hyman BT, Jack CR Jr, Kawas CH, Klunk WE, Koroshetz WJ, Manly JJ, Mayeux R, Mohs RC, Morris JC, Rossor MN, Scheltens P, Carrillo MC, Thies B, Weintraub S, Phelps $\mathrm{CH}$ (2011) The diagnosis of dementia due to Alzheimer's disease: recommendations from the National Institute on Aging-Alzheimer's Association workgroups on diagnostic guidelines for Alzheimer's disease. Alzheimers Dement 7:263-269. 
Meister M (2016) Physical limits to magnetogenetics. eLife 5:e17210.

Mohebi A, Pettibone JR, Hamid AA, Wong JT, Vinson LT, Patriarchi T, Tian L, Kennedy RT, Berke JD (2019) Dissociable dopamine dynamics for learning and motivation. Nature 570:65-70.

Morales M, Margolis EB (2017) Ventral tegmental area: cellular heterogeneity, connectivity and behaviour. Nat Rev Neurosci 18:73-85.

Muller A, Joseph V, Slesinger PA, Kleinfeld D (2014) Cell-based reporters reveal in vivo dynamics of dopamine and norepinephrine release in murine cortex. Nat Methods 11:1245-1252.

Nadim F, Bucher D (2014) Neuromodulation of neurons and synapses. Curr Opin Neurobiol 29:48-56.

Neher E (2015) Merits and limitations of vesicle pool models in view of heterogeneous populations of synaptic vesicles. Neuron 87:1131-1142.

Okaty BW, Commons KG, Dymecki SM (2019) Embracing diversity in the 5-HT neuronal system. Nat Rev Neurosci 20:397-424.

Olive MF, Mehmert KK, Hodge CW (2000) Microdialysis in the mouse nucleus accumbens: a method for detection of monoamine and amino acid neurotransmitters with simultaneous assessment of locomotor activity. Brain Res Brain Res Protoc 5:16-24.

Patriarchi T, Cho JR, Merten K, Howe MW, Marley A, Xiong WH, Folk RW, Broussard GJ, Liang RQ, Jang MJ, Zhong HN, Dombeck D, von Zastrow M, Nimmerjahn A, Gradinaru V, Williams JT, Tian L (2018) Ultrafast neuronal imaging of dopamine dynamics with designed genetically encoded sensors. Science 360:eaat4422.

Patriarchi T, Cho JR, Merten K, Marley A, Broussard GJ, Liang R, Williams J, Nimmerjahn A, von Zastrow M, Gradinaru V, Tian L (2019) Imaging neuromodulators with high spatiotemporal resolution using genetically encoded indicators. Nat Protoc 14:3471-3505.

Patriarchi T, Mohebi A, Sun J, Marley A, Liang R, Dong C, Puhger K, Mizuno GO, Davis CM, Wiltgen B, von Zastrow M, Berke JD, Tian L (2020) An expanded palette of dopamine sensors for multiplex imaging in vivo. Nat Methods 17:1147-1155.

Piatkevich KD, Jung EE, Straub C, Linghu C, Park D, Suk HJ, Hochbaum DR, Goodwin D, Pnevmatikakis E, Pak N, Kawashima T, Yang CT, Rhoades JL, Shemesh O, Asano S, Yoon YG, Freifeld L, Saulnier JL, Riegler C, Engert F, et al. (2018) A robotic multidimensional directed evolution approach applied to fluorescent voltage reporters. Nat Chem Biol 14:352-360.

Picciotto MR, Higley MJ, Mineur YS (2012) Acetylcholine as a neuromodulator: cholinergic signaling shapes nervous system function and behavior. Neuron 76:116-129.

Pulido C, Marty A (2017) Quantal fluctuations in central mammalian synapses: functional role of vesicular docking sites. Physiol Rev 97:1403-1430.

Ravindran LN, Stein MB (2010) The pharmacologic treatment of anxiety disorders: a review of progress. J Clin Psychiatry 71:839-854.

Rial RV, Canellas F, Gamundi A, Akaarir M, Nicolau MC (2018) Pleasure: the missing link in the regulation of sleep. Neurosci Biobehav Rev 88:141-154.

Robinson DL, Hermans A, Seipel AT, Wightman RM (2008) Monitoring rapid chemical communication in the brain. Chem Rev 108:2554-2584.

Ruiz R, Cano R, Casanas JJ, Gaffield MA, Betz WJ, Tabares L (2011) Active zones and the readily releasable pool of synaptic vesicles at the neuromuscular junction of the mouse. J Neurosci 31:2000-2008.

Rusakov DA, Kullmann DM, Stewart MG (1999) Hippocampal synapses: do they talk to their neighbours? Trends Neurosci 22:382-388.

Sabatini BL, Tian L (2020) Imaging neurotransmitter and neuromodulator dynamics in vivo with genetically encoded indicators. Neuron 108:17-32.

Samulski RJ, Muzyczka N (2014) AAV-mediated gene therapy for research and therapeutic purposes. Annu Rev Virol 1:427-451.

Sara SJ, Bouret S (2012) Orienting and reorienting: the locus coeruleus mediates cognition through arousal. Neuron 76:130-141.

Sarter M, Parikh V, Howe WM (2009) Phasic acetylcholine release and the volume transmission hypothesis: time to move on. Nat Rev Neurosci 10:383-390.

Sauer M (2013) Localization microscopy coming of age: from concepts to biological impact. J Cell Sci 126:3505-3513.

Savtchenko LP, Rusakov DA (2007) The optimal height of the synaptic cleft. Proc Natl Acad Sci USA 104:1823-1828.

Savtchenko LP, Sylantyev S, Rusakov DA (2013) Central synapses release a resource-efficient amount of glutamate. Nat Neurosci 16:10-12.

Scammell TE, Arrigoni E, Lipton JO (2017) Neural circuitry of wakefulness and sleep. Neuron 93:747-765.
Schneggenburger R, Meyer AC, Neher E (1999) Released fraction and total size of a pool of immediately available transmitter quanta at a calyx synapse. Neuron 23:399-409.

Schultz W (2016) Dopamine reward prediction-error signalling: a two-component response. Nat Rev Neurosci 17:183-195.

Schwarz LA, Luo LQ (2015) Organization of the locus coeruleus-norepinephrine system. Curr Biol 25:R1051-R1056.

Servick K (2019) War of nerves. Science 365:1071-1073.

Shivange AV, Borden PM, Muthusamy AK, Nichols AL, Bera K, Bao H, Bishara I, Jeon J, Mulcahy MJ, Cohen B, O'Riordan SL, Kim C, Dougherty DA, Chapman ER, Marvin JS, Looger LL, Lester HA (2019) Determining the pharmacokinetics of nicotinic drugs in the endoplasmic reticulum using biosensors. J Gen Physiol 151:738-757.

Sibarita JB (2005) Deconvolution microscopy. Adv Biochem Eng Biotechnol 95:201-243.

Simic G, Leko MB, Wray S, Harrington CR, Delalle I, Jovanov-Milosevic N, Bazadona D, Buee L, de Silva R, Di Giovanni G, Wischik CM, Hof PR (2017) Monoaminergic neuropathology in Alzheimer's disease. Prog Neurobiol 151:101-138.

Sudhof TC (2018) Towards an understanding of synapse formation. Neuron 100:276-293.

Sun F, Zeng J, Jing M, Zhou J, Feng J, Owen SF, Luo Y, Li F, Wang H, Yamaguchi T, Yong Z, Gao Y, Peng W, Wang L, Zhang S, Du J, Lin D, Xu M, Kreitzer AC, Cui G, et al. (2018) A genetically encoded fluorescent sensor enables rapid and specific detection of dopamine in flies, fish, and mice. Cell 174:481-496.

Sun F, Zhou J, Dai B, Qian T, Zeng J, Li X, Zhuo Y, Zhang Y, Wang Y, Qian C, Tan K, Feng J, Dong H, Lin D, Cui G, Li Y (2020) New and improved GRAB fluorescent sensors for monitoring dopaminergic activity in vivo. Nat Methods 17:1156-1166.

Sykova E, Nicholson C (2008) Diffusion in brain extracellular space. Physiol Rev 88:1277-1340.

Thanawala MS, Regehr WG (2013) Presynaptic calcium influx controls neurotransmitter release in part by regulating the effective size of the readily releasable pool. J Neurosci 33:4625-4633.

Thanawala MS, Regehr WG (2016) Determining synaptic parameters using high-frequency activation. J Neurosci Methods 264:136-152.

Unger EK, Keller JP, Altermatt M, Liang R, Matsui A, Dong C, Hon OJ, Yao Z, Sun J, Banala S, Flanigan ME, Jaffe DA, Hartanto S, Carlen J, Mizuno GO, Borden PM, Shivage AV, Cameron LP, Sinning S, Underhill SM, et al. (2020) Directed evolution of a selective and sensitive serotonin sensor via machine learning. Cell 183:1986-2002.e26.

Uyaniker S, van der Spek SJ, Reinders NR, Xiong H, Li KW, Bossers K, Smit AB, Verhaagen J, Kessels HW (2019) The effects of Sindbis viral vectors on neuronal function. Front Cell Neurosci 13:362.

Vilardaga JP, Bunemann M, Krasel C, Castro M, Lohse MJ (2003) Measurement of the millisecond activation switch of $\mathrm{G}$ protein-coupled receptors in living cells. Nat Biotechnol 21:807-812.

Villette V, Chavarha M, Dimov IK, Bradley J, Pradhan L, Mathieu B, Evans SW, Chamberland S, Shi D, Yang R, Kim BB, Ayon A, Jalil A, St-Pierre F, Schnitzer MJ, Bi G, Toth K, Ding J, Dieudonné S, Lin MZ (2019) Ultrafast two-photon imaging of a high-gain voltage indicator in awake behaving mice. Cell 179:1590-1608.e1523.

Volk L, Chiu SL, Sharma K, Huganir RL (2015) Glutamate synapses in human cognitive disorders. Annu Rev Neurosci 38:127-149.

Volkow ND, Michaelides M, Baler R (2019) The neuroscience of drug reward and addiction. Physiol Rev 99:2115-2140.

Wan J, Peng W, Li X, Qian T, Song K, Zeng J, Deng F, Hao S, Feng J, Zhang P, Zhang Y, Zou J, Pan S, Shin M, Venton BJ, Zhu JJ, Jing M, Xu M, Li Y (2020) A genetically encoded sensor for measuring serotonin dynamics. Nat Neurosci In press.

Wang D, Tai PW, Gao G (2019) Adeno-associated virus vector as a platform for gene therapy delivery. Nat Rev Drug Discov 18:358-378.

Wang G, Wyskiel DR, Yang W, Wang Y, Milbern LC, Lalanne T, Jiang X, Shen Y, Sun QQ, Zhu JJ (2015a) An optogenetics- and imaging-assisted simultaneous multiple patch-clamp recordings system for decoding complex neural circuits. Nat Protoc 10:397-412.

Wang G, Bochorishvili G, Chen Y, Salvati KA, Zhang P, Dubel SJ, PerezReyes E, Snutch TP, Stornetta RL, Deisseroth K, Erisir A, Todorovic SM, Luo JH, Kapur J, Beenhakker MP, Zhu JJ (2015b) Cav 3.2 calcium channels control NMDA receptor-mediated transmission: a new mechanism for absence epilepsy. Genes Dev 29:1535-1551. 
Wang G, Zhang P, Mendu SK, Wang Y, Zhang Y, Kang X, Desai BN, Zhu JJ (2020) Revaluation of magnetic properties of Magneto. Nat Neurosci 23:1047-1050.

Wang H, Jing M, Li Y (2018) Lighting up the brain: genetically encoded fluorescent sensors for imaging neurotransmitters and neuromodulators. Curr Opin Neurobiol 50:171-178.

Weber F, Dan Y (2016) Circuit-based interrogation of sleep control. Nature 538:51-59.

Weigert M, Schmidt U, Boothe T, Müller A, Dibrov A, Jain A, Wilhelm B, Schmidt D, Broaddus C, Culley S, Rocha-Martins M, Segovia-Miranda F, Norden C, Henriques R, Zerial M, Solimena M, Rink J, Tomancak P, Royer L, Jug F, et al. (2018) Content-aware image restoration: pushing the limits of fluorescence microscopy. Nat Methods 15:1090-1097.

Wessler I, Kirkpatrick CJ (2008) Acetylcholine beyond neurons: the nonneuronal cholinergic system in humans. Br J Pharmacol 154:1558-1571.

Wood SK, Valentino RJ (2017) The brain norepinephrine system, stress and cardiovascular vulnerability. Neurosci Biobehav Rev 74:393-400.

Zahalka AH, Frenette PS (2020) Nerves in cancer. Nat Rev Cancer 20:143157.
Zemek F, Drtinova L, Nepovimova E, Sepsova V, Korabecny J, Klimes J, Kuca K (2014) Outcomes of Alzheimer's disease therapy with acetylcholinesterase inhibitors and memantine. Expert Opin Drug Saf 13:759-774.

Zhang L, Zhang P, Wang G, Zhang H, Zhang Y, Yu Y, Zhang M, Xiao J, Crespo P, Hell JW, Lin L, Huganir RL, Zhu JJ (2018) Ras and Rap signal bidirectional synaptic plasticity via distinct subcellular microdomains. Neuron 98:783-800.

Zheng K, Jensen TP, Savtchenko LP, Levitt JA, Suhling K, Rusakov DA (2017) Nanoscale diffusion in the synaptic cleft and beyond measured with time-resolved fluorescence anisotropy imaging. Sci Rep 7:42022.

Zhu JJ (2009) Activity level-dependent synapse-specific AMPA receptor trafficking regulates transmission kinetics. J Neurosci 29:6320-6335.

Zhu PK, Zheng WS, Zhang P, Jing M, Borden PM, Ali F, Guo K, Feng J, Marvin JS, Wang Y, Wan J, Gan L, Kwan AC, Lin L, Looger LL, Li Y, Zhang Y (2020) Nanoscopic visualization of restricted non-volume cholinergic and monoaminergic transmission with genetically encoded sensors. Nano Lett 20:4073-4083.

Zoli M, Jansson A, Sykova E, Agnati LF, Fuxe K (1999) Volume transmission in the CNS and its relevance for neuropsychopharmacology. Trends Pharmacol Sci 20:142-150. 